University of Nebraska - Lincoln

DigitalCommons@University of Nebraska - Lincoln

Faculty Publications: Department of Entomology

Entomology, Department of

8-2-2019

\title{
Bacteria-mediated modification of insecticide toxicity in the yellow fever mosquito, Aedes aegypti
}

\author{
Sara S. Scates \\ Virginia Tech \\ Scott T. O'Neal \\ University of Nebraska - Lincoln, soneal3@unl.edu \\ Troy D. Anderson \\ University of Nebraska - Lincoln, tanderson44@unl.edu
}

Follow this and additional works at: https://digitalcommons.unl.edu/entomologyfacpub

Part of the Entomology Commons, and the Public Health Commons

Scates, Sara S.; O'Neal, Scott T.; and Anderson, Troy D., "Bacteria-mediated modification of insecticide toxicity in the yellow fever mosquito, Aedes aegypti" (2019). Faculty Publications: Department of Entomology. 821.

https://digitalcommons.unl.edu/entomologyfacpub/821

This Article is brought to you for free and open access by the Entomology, Department of at DigitalCommons@University of Nebraska - Lincoln. It has been accepted for inclusion in Faculty Publications: Department of Entomology by an authorized administrator of DigitalCommons@University of Nebraska - Lincoln. 


\title{
Bacteria-mediated modification of insecticide toxicity in the yellow fever mosquito, Aedes aegypti
}

\author{
Sara S. Scates, 1 Scott T. O'Neal,2 \& Troy D. Anderson 2
}

\author{
1 Department of Entomology, Virginia Tech, Blacksburg, VA, USA \\ 2 Department of Entomology, University of Nebraska, Lincoln, NE, USA \\ Corresponding author - T.D. Anderson, email tanderson44@unl.edu
}

\begin{abstract}
The incidence of mosquito-borne disease poses a significant threat to human and animal health throughout the world, with effective chemical control interventions limited by widespread insecticide resistance. Recent evidence suggests that gut bacteria of mosquitoes, known to be essential in nutritional homeostasis and pathogen defense, may also play a significant role in facilitating insecticide resistance. This study investigated the extent to which bacteria contribute to the general esterase and cytochrome P450 monooxygenase (P450)-mediated detoxification of the insecticides propoxur and naled, as well as the insecticidal activity of these chemistries to the yellow fever mosquito, Aedes aegypti. Experiments conducted using insecticide synergists that reduce general esterase and P450 activity demonstrate a role for both groups of enzymes in the metabolic detoxification of propoxur and naled. Furthermore, reduction of bacteria in mosquito larvae using broad-spectrum antibiotics was found to decrease the metabolic detoxification of propoxur and naled, suggesting that the bacteria themselves may be contributing to the in vivo metabolic
\end{abstract}

Published in Pesticide Biochemistry and Physiology 161 (2019), pp 77-85.

doi 10.1016/j.pestbp.2019.07.016

Copyright (C) 2019. Published by Elsevier Inc. Used by permission.

Submitted 14 June 2019; revised 24 July 2019; accepted 31 July 2019;

published 2 August 2019. 
detoxification of these insecticides. This was supported by in vitro assays using culturable gut bacteria isolated from mosquito larvae which demonstrated that the bacteria were capable of reducing insecticide toxicity. More work is needed, however, to fully elucidate the contribution of bacteria in Ae. aegypti larvae to the metabolic detoxification of insecticides.

Keywords: mosquito, Aedes aegypti, insecticide resistance, bacteria, synergists, antibiotics

\section{Introduction}

Aedes aegypti is a highly anthropophilic, day-biting mosquito with global distribution that is a major vector of the viral pathogens that cause dengue, chikungunya, and yellow fever, among others. The elimination of mosquito larval habitats and application of insecticides remains the primary approach for limiting viral transmission (Morrison et al., 2008); however, the increasing incidence of insecticide resistance limits the efficacy of many currently used larvicides and adulticides for Ae. aegypti control. This problem is further exacerbated by the slow pace at which new insecticides have been developed and marketed for the chemical control of Ae. aegypti in recent decades (Hemingway et al., 2006). Therefore, a thorough understanding of insecticide resistance mechanisms is essential for enhancing the efficacy of existing chemical interventions and for the development of novel vector management practices for these mosquitoes.

Mosquito acetylcholinesterase (AChE) is a proven target site for two major insecticide families: the organophosphates and carbamates. AChE is a serine hydrolase responsible for terminating synaptic transmission at cholinergic synapses in the central nervous system of mosquitoes by rapidly hydrolyzing the neurotransmitter acetylcholine (Weill et al., 2002). When AChE is inhibited by organophosphate and carbamate insecticides, paralysis and subsequent death of the insect occurs. Naled (Dibrom ${ }^{\circledR}$ ) and propoxur (Baygon ${ }^{\circledR}$ ) are examples of insecticides commonly used for the control of Ae. aegypti. Naled is an organophosphate insecticide most often applied through aerial spraying to target larval and adult mosquitoes, whereas propoxur is a carbamate insecticide used for indoor residual spraying to control adult mosquitoes. While naled and propoxur are potent acetylcholinesterase inhibitors, the increasing incidence of resistance reduces their efficacy when used for the control of mosquitoes. Resistance to 
insecticides can be the result of one or more general mechanisms that can be categorized as behavioral, reduced cuticular penetration, target site insensitivity, enhanced metabolic detoxification activity, or other toxicokinetic interactions such as transport, sequestration, and elimination. Of these general mechanisms, enhanced metabolic detoxification may have the broadest impact as it can produce cross resistance to multiple classes of insecticides, regardless of the mode of action.

Metabolic resistance involves enhanced levels or altered activities of enzyme families associated with detoxification, the most significant of which are the general esterases, the cytochrome P450 monooxygenases (P450), and the glutathione $S$-transferases. These enzymes recognize and transform functional groups to reduce reactivity and increase polarity (Phase I) and conjugate them to endogenous molecules for excretion (Phase II) (Casida and Quistad, 2004). The general esterases and P450s represent two major enzyme groups that are responsible for metabolic resistance to organophosphates, organochlorines, carbamates, and pyrethroids (Hemingway, 2000). The general esterases have been associated with organophosphate, carbamate, and less frequently, pyrethroid resistance, whereas the P450s are involved in metabolic detoxification of pyrethroids, the activation and inactivation of organophosphates, and occasionally carbamate detoxification (Hemingway, 2000).

An important tool used both to understand and to counteract insecticide resistance conferred by metabolic detoxification enzymes is the use of chemical synergists. Synergists are typically non-toxic to insects when applied alone, but when applied in combination with insecticides, result in increased efficacy of the insecticide against the targeted pest. The synergists piperonyl butoxide (PBO), S,S,S-tributyl phosphorotrithioate (DEF), and triphenyl phosphate (TPP) have been used to provide preliminary assessments of the contribution of metabolic detoxification enzymes, such as P450s and esterases, in insecticide resistant insects. PBO, a methyldioxyphenyl synergist, can inhibit P450- dependent metabolism and, in turn, increase the efficacy of insecticides (Matthews and Casida, 1970), whereas TPP and DEF, both organophosphate esterase inhibitors, are reported to inhibit hydrolases that decrease the efficacy of insecticides (Bernard and Philogène, 1993). While this detoxification enzyme activity is generally assumed to be the result of proteins encoded and expressed by the insect itself, there is growing evidence that suggests a role for the insect 
microbiome in the detoxification of insecticides and other toxic compounds (Kikuchi et al., 2012; Gadad and Vastrad, 2016; Cheng et al., 2017; Soltani et al., 2017; Xia et al., 2018).

Insects can harbor large ecological communities of diverse microorganisms that comprise the microbiome of that organism. Extensive research has focused on the contribution of gut bacteria and other microbial symbionts to host reproduction (Haine, 2008) and mate selection (Werren et al., 2008), nutritional homeostasis (Dillon and Dillon, 2004), phenotypic complexity (Moran, 2007), as well as pathogen defense (Hedges et al., 2008; Dong et al., 2009; Hoffmann et al., 2011; Eleftherianos et al., 2013). Some bacteria have the ability to metabolize organophosphates and use them as sources of carbon, phosphorous, or nitrogen, facilitating degradation of these compounds in the environment (Werren, 2012). Bacterial symbionts have even been implicated in the development of insecticide resistance in their insect hosts, such as the bean bug Riportus pedestris, which has been reported to harbor mutualistic gut symbionts of the genus Burkholderia that are capable of degrading organophosphate insecticides and contribute to the enhanced insecticide resistance of this insect pest (Kikuchi et al., 2012). Gut bacteria of the genus Citrobacter have been shown to enhance resistance of the tephritid pest Bactrocera dorsalis to the organophosphate insecticide trichlorphon (Cheng et al., 2017), while Enterococcus sp. appear to similarly enhance resistance to another organophosphate, chlorpyrifos, in the diamondback moth, Plutella xylostella (Xia et al., 2018). Gut bacteria have also been found to play a significant role in the resistance of the mosquito species Anopheles stephensi to organophosphate insecticides (Soltani et al., 2017).

While many of these insecticide-degrading symbionts have been characterized for other insect pests, there is limited information available regarding insecticide-metabolizing bacteria species that could establish a symbiotic association and confer insecticide resistance in mosquitoes, and no studies that focus specifically on Ae. aegypti. Therefore, the hypothesis of this study is that gut bacteria of Ae. aegypti larvae contribute to the metabolic detoxification and toxic action of the insecticides naled and propoxur. Here, we examined the acute toxicities of naled and propoxur to mosquito larvae, as well as the general esterase and P450 activities of these mosquitoes following treatment with 1) insecticide synergists and 2) broad-spectrum antibiotics. The data gathered in this study provide new information 
regarding the role of bacteria in mosquito larvae to alter the toxic action of insecticides used to manage mosquitoes.

\section{Materials and methods}

\subsection{Mosquito strains}

A laboratory colony of Aedes aegypti (Liverpool strain) was obtained from the Malaria Research and Reference Reagent Resource Center (MR4) (Manassas, VA, USA) and maintained at Virginia Tech (Blacksburg, VA, USA) according to the standard operating procedures described by Pridgeon et al. (Pridgeon et al., 2009), with slight modifications. The adult mosquitoes were held in a screened cage and provided $10 \%$ sucrose ad libitum. To encourage egg development, adult females were provided with defibrinated sheep blood (Colorado Serum Co., Denver, CO, USA) that was warmed to $37^{\circ} \mathrm{C}$ using an artificial membrane mosquito feeder (Chemglass Life Sciences LLC, Vineland, NJ). Eggs were collected from the adult females and vacuum-hatched in a $1 \mathrm{~L}$ Erlenmeyer flask, then larvae were transferred to a plastic tray containing deionized water. A larval diet of unsterilized flake fish food (Tetramin, Blacksburg, VA, USA) was added to the plastic tray as needed. The mosquito larvae and adults were reared in an environmental chamber at $28{ }^{\circ} \mathrm{C}$ and $75 \%$ relative humidity with a $16 \mathrm{~h}: 8 \mathrm{~h}$ (light:dark) photoperiod.

\subsection{Chemicals}

Acetone, gentamicin sulfate, benzylpenicillin sodium, streptomycin sulfate, sodium phosphate, Triton X-100, $\alpha$-naphthyl acetate $(\alpha-N A)$, $\alpha$-naphthol, bicinchoninic acid solution, bovine serum albumin, 7-ethoxycoumarin (7-EC), acetonitrile, TRIZMA-base, acetylthiocholine iodide (ATCh), and 5,5'-dithio-bis (2-nitrobenzoic acid) (DTNB) were obtained from Sigma-Aldrich (St. Louis, MO, USA). 2-isopropoxyphenyl $\mathrm{N}$-methylcarbamate (propoxur), dimethyl-1,2-dibromo-2,2-dichlorethyl phosphate (naled), triphenyl phosphate (TPP), S,S,S-tributyl phosphorotrithioate (DEF), and piperonyl butoxide (PBO) were obtained from Chem Service, Inc. (West Chester, PA, USA). All chemicals were obtained as technical grade or at the highest purity available. 


\subsection{Acute toxicity of insecticides with and without synergist and antibiotics}

For all acute toxicity bioassays, the test compounds were diluted to the appropriate concentration in acetone and delivered by adding 5 $\mu \mathrm{L}$ of solution to $5 \mathrm{~mL}$ of deionized water containing ten third-instar mosquito larvae in a $10 \mathrm{ml}$ glass beaker. Acetone alone was used as a control treatment and bioassays were repeated three times for each treatment. Treated larvae were maintained in an environmental chamber at $28{ }^{\circ} \mathrm{C}$ and $75 \%$ relative humidity with a $16 \mathrm{~h}: 8 \mathrm{~h}$ (light:dark) photoperiod. The endpoint for each bioassay was measured as a lethal concentration (LC) and larvae that were unable to perform an active movement upon gentle probing were considered dead. To assess the acute toxicity of propoxur and naled, groups of larvae were exposed for $24 \mathrm{~h}$ to acetone or one of five concentrations of either insecticide to produce a range of 0 to $100 \%$ mortality. To assess the combined effect of propoxur or naled with synergists, groups of larvae were exposed to acetone, TPP at $2000 \mu \mathrm{g} / \mathrm{L}$ (parts per billion or ppb), DEF at $500 \mathrm{ppb}$, or PBO at $2500 \mathrm{ppb}$ for $12 \mathrm{~h}$ prior to treatment with acetone or an insecticide at one of five concentrations, as described above. Synergist exposures were optimized for time and concentration with the goal of obtaining maximal inhibition of the desired enzymes without any larval mortality. To assess the combined effect of propoxur and naled with antibiotics, groups of larvae were exposed to either acetone or a combination of the antibiotics gentamicin sulfate (1500 $\mu \mathrm{g} / \mathrm{mL}$ ), benzylpenicillin sodium (1000 units/ $\mathrm{mL}$ ), and streptomycin sulfate $(1 \mathrm{mg} / \mathrm{mL})$ for $12 \mathrm{~h}$ prior to treatment with acetone or an insecticide at one of five concentrations described above.

\subsection{Detoxification enzyme activity}

\subsubsection{In vivo inhibition of detoxification enzyme activity}

Third-instar mosquito larvae were exposed individually to propoxur or naled at the $\mathrm{LC}_{25}$ for bioassays of $\mathrm{P} 450$ and general esterase activities, or at the $\mathrm{LC}_{10}$ for bioassays of AChE activity, and in combination with TPP (2000 ppb), DEF (500 ppb), or PBO (2500 ppb) for $12 \mathrm{~h}$ prior to insecticide treatment. The synergist stock solutions were prepared in acetone and $5 \mu \mathrm{L}$ of each solution was dissolved in $5 \mathrm{~mL}$ of deionized water containing 10 larvae. The treated larvae were maintained 
in an environmental chamber at $28{ }^{\circ} \mathrm{C}$ and $75 \%$ relative humidity with a $16 \mathrm{~h}: 8 \mathrm{~h}$ (light:dark) photoperiod. Larval mortality was assessed for each treatment and all surviving mosquitoes were collected from each treatment for the metabolic detoxification enzyme activity bioassays. The procedure was replicated three times for the control (synergist untreated), synergist alone treatment, and synergist-insecticide treatments.

\subsubsection{Effect of antibiotic treatments on enzyme activity}

Mosquito larvae were also exposed to the insecticides at the $\mathrm{LC}_{25}$ alone and in combination with the antibiotic mixture. Larval mortality was assessed for each treatment and all surviving mosquitoes were collected from each treatment for the metabolic detoxification enzyme activity bioassays. The procedure was replicated three times for the control (antibiotic untreated) and antibiotic treatments.

\subsubsection{General esterase activity}

The general esterase activity of treated larvae was measured according to the method described by Rakotondravelo et al. (Rakotondravelo et al., 2006). Each mosquito sample was homogenized in icecold $0.1 \mathrm{M}$ sodium phosphate $(\mathrm{pH} 7.8)$ containing $0.3 \%(\mathrm{v} / \mathrm{v})$ Triton $\mathrm{X}-100$ at the rate of one mosquito larva per $100 \mu \mathrm{L}$ sodium phosphate. The individual homogenates were centrifuged at $10,000 \times g$ for 10 min at $4{ }^{\circ} \mathrm{C}$. The supernatant served as the enzyme source for measuring general esterase activity using $0.3 \mathrm{mM} \alpha-\mathrm{NA}$ as a substrate. The hydrolysis of $\alpha$-NA to the product $\alpha$-naphthol was measured using a Molecular Devices SpectraMax M2 multimode microplate reader (Sunnyvale, CA, USA) at $600 \mathrm{~nm}$ for $\alpha-N A$. The total protein in each sample preparation was determined using a bicinchoninic acid assay as described by Smith et al. (Smith et al., 1985), with bovine serum albumin as a standard. The amount of protein in each sample was measured at $560 \mathrm{~nm}$.

\subsubsection{Cytochrome P450 monooxygenase activity}

The P450 activity of treated larvae was measured according to the method described by Anderson and Zhu (Anderson and Zhu, 2004), with some modifications. Following treatment, the individual live larvae were transferred to the wells of a 96-well microplate containing $50 \mathrm{mM}$ sodium phosphate $(\mathrm{pH} 7.2)$ and $0.4 \mathrm{mM} 7$-ethoxycoumarin. 
The larvae were incubated at $37^{\circ} \mathrm{C}$ for $4 \mathrm{~h}$ followed by the addition of $50 \%(\mathrm{v} / \mathrm{v})$ acetonitrile and Trizma base $(\mathrm{pH} 10)$. The reaction buffer was then removed from the microplate wells and transferred into wells of a new microplate, being careful not to aspirate any larvae. The deethylation of 7-ethoxycoumarin to the product 7-hydroxycoumarin was measured using a Molecular Devices SpectraMax M2 multimode microplate reader (Sunnyvale, CA, USA) at $480 \mathrm{~nm}$ while exciting at $380 \mathrm{~nm}$.

\subsubsection{Acetylcholinesterase activity}

The AChE activity of treated larvae was determined according to the method of Ellman et al. (Ellman et al., 1961), as modified by Anderson et al. (Anderson et al., 2009). Each mosquito sample was homogenized in ice-cold $0.1 \mathrm{M}$ sodium phosphate buffer ( $\mathrm{pH} 7.8$ ) containing $0.3 \%(\mathrm{v} / \mathrm{v})$ Triton $\mathrm{X}-100$ at the rate of one mosquito larva per $100 \mu \mathrm{L}$ sodium phosphate. The individual homogenates were centrifuged at $10,000 \times g$ for $10 \mathrm{~min}$ at $4{ }^{\circ} \mathrm{C}$ and the supernatant was used as the enzyme source for measuring AChE activity with ATCh and DTNB. The hydrolysis of ATCh and the formation of thionitrobenzoic acid was measured using a Molecular Devices SpectraMax M2 multimode microplate reader (Sunnyvale, CA, USA) at $405 \mathrm{~nm}$.

\subsection{Antibiotic treatment}

Third-instar mosquito larvae were exposed to a mixture of antibiotics containing gentamicin sulfate $(1500 \mu \mathrm{g} / \mathrm{mL})$, benzylpenicillin sodium (1000 units $/ \mathrm{mL})$, and streptomycin sulfate $(1 \mathrm{mg} / \mathrm{mL})$ for $12 \mathrm{~h}$. The antibiotic stock solutions were prepared in sterilized water and each solution was dissolved in $5 \mathrm{~mL}$ of deionized water containing 10 larvae. The treated larvae were maintained in an environmental chamber at $28{ }^{\circ} \mathrm{C}$ and $75 \%$ relative humidity with a $16 \mathrm{~h}: 8 \mathrm{~h}$ (light:dark) photoperiod. Larval mortality was assessed for each treatment and the procedure was replicated three times for the control (antibiotic untreated) and antibiotic treatments. After these exposures, mosquitoes were homogenized in a PBS solution $(\mathrm{pH} 7.4)$ and centrifuged at 10,000 $\times g$. The supernatants were then serially diluted up to $10^{6}$ and plated onto Luria Bertani (LB) agar plates (Sigma-Aldrich, St. Louis, MO, USA). The plates were incubated at $28^{\circ} \mathrm{C}$ for $48 \mathrm{~h}$, after which time colony forming units (CFU) were determined. 


\subsection{Insecticide degradation activity}

Davis minimal broth medium supplemented with casein (DMMC) was prepared by supplementing the Davis minimal media described by Lederberg (Lederberg, 1950) with $10 \mathrm{~g} / \mathrm{L}$ casein from bovine milk (Sigma-Aldrich, St. Louis, MO, USA). Propoxur or naled were prepared and added separately to flasks containing $5 \mathrm{~mL}$ of DMMC. The flasks were inoculated with a homogenate of Ae. aegypti larvae. Additional flasks were prepared with either DMMC or DMMC supplemented with naled or propoxur, but no larval homogenate, as a control treatment. After 12-, 24-, and 48-h incubation, $100 \mu \mathrm{L}$ of growth medium ( $\mathrm{LC}_{50}$ of propoxur and naled) was transferred to 4.9 $\mathrm{mL}$ of water containing 10 mosquito larvae. Percent mortality was assessed $24 \mathrm{~h}$ post treatment.

\subsection{Statistical analysis}

Log-probit analysis was used to estimate the $\mathrm{LC}_{10}, \mathrm{LC}_{25}$, and $\mathrm{LC}_{50}$ values for each insecticide, both alone and in combination with the synergists. Abbott's correction (Abbott, 1925) was utilized to account for mortality in the controls. Synergistic ratios (SR) were calculated by dividing the $\mathrm{LC}_{50}$ of the insecticide-only treatments by the $\mathrm{LC}_{50}$ of the insecticide+synergist or antibiotic treatments (e.g., $\mathrm{SR}=\mathrm{LC}_{50}$ insecticide- only $\div \mathrm{LC} C_{50}$ insecticide+synergist $)$. The significant differences between the $\mathrm{LC}_{50}$ for each insecticide, alone and in combination with the synergist treatments, was based on the non-overlapping 95\% confidence intervals estimated for each bioassay. The percentage of mosquitoes affected by the different treatments was statistically compared using a one-way ANOVA and a Tukey's multiple comparison post hoc test. Differences in mortality or enzyme activity based on treatments were determined by statistical comparisons between groups using a two-way ANOVA followed by Sidak's multiple comparison test. All statistical tests were carried out at a significance level $(\alpha)$ of 0.05 . All calculations and statistical analyses were conducted using GraphPad Prism 7 (GraphPad Software, Inc., La Jolla, CA, USA). 


\section{Results}

\subsection{Acute toxicity of insecticides with and without synergist and antibiotics}

The results of the acute toxicity bioassays of insecticides alone and in combination with synergists are summarized in Table 1. The synergists TPP, DEF, and PBO at 2000 ppb, 500 ppb, and 2500 ppb, respectively, were not acutely toxic to third-instar Ae. aegypti larvae under the bioassay conditions. The $\mathrm{LC}_{50}$ estimates for propoxur or naled alone and in combination with TPP, DEF, and PBO were used to calculate synergism ratios. The toxicity of propoxur was significantly increased by 1.31-, 2.37-, and 4.47-fold when applied in combination with a fixed concentration of TPP, DEF, or PBO, respectively. In addition, the toxicity of naled was significantly increased by 3.39- and 5.61-fold when in combination with a fixed concentration of TPP or DEF, respectively. The toxicity of naled was slightly decreased when in combination with a fixed concentration of PBO; however, this alteration of toxicity was not significant based on the overlapping $95 \%$ confidence intervals of their $\mathrm{LC}_{50}$ estimates.

Table 1. Effects of triphenyl phosphate (TPP, $2000 \mu \mathrm{g} / \mathrm{L}), \mathrm{S}, \mathrm{S}, \mathrm{S}$-tributyl phosphorotrithioate (DEF, $500 \mu \mathrm{g} / \mathrm{L})$, and piperonyl butoxide (PBO, $2500 \mu \mathrm{g} / \mathrm{L}$ ) on the acute toxicity of propoxur or naled to third-instar Aedes aegypti larvae.

\begin{tabular}{llllllll} 
Insecticidea & $N$ & $\mathrm{LC}_{10}(95 \% \mathrm{Cl})$ & $\mathrm{LC}_{25}(95 \% \mathrm{Cl})$ & $\mathrm{LC}_{50}(95 \% \mathrm{Cl})$ & Slope $\pm \mathrm{SE}$ & $\chi^{2 \mathrm{~b}}$ & $\mathrm{SRc}^{\mathrm{c}}$ \\
\hline Propoxur & 540 & $339(266-398)$ & $453(383-512)$ & $626(559-694)$ & $4.80 \pm 0.35$ & 2.43 & \\
+ TPP & 150 & $264(194-320)$ & $349(280-406)$ & $477(411-541)$ & $4.99 \pm 0.69$ & 0.57 & $1.31^{*}$ \\
+ DEF & 150 & $123(60-176)$ & $177(104-233)$ & $264(189-323)$ & $3.87 \pm 0.73$ & 0.40 & $2.37^{*}$ \\
+ PBO & 390 & $32(21-44)$ & $62(45-79)$ & $126(101-157)$ & $2.70 \pm 0.28$ & 1.47 & $4.97^{*}$ \\
Naled & 900 & $17(15-20)$ & $25(22-28)$ & $38(35-43)$ & $3.69 \pm 0.21$ & 1.84 & \\
+ TPP & 150 & $6(4-7)$ & $8(6-10)$ & $11(10-13)$ & $4.47 \pm 0.73$ & 0.63 & $3.39^{*}$ \\
+ DEF & 150 & $3(1-5)$ & $5(3-6)$ & $7(5-8)$ & $3.86 \pm 0.87$ & 0.21 & $5.61^{*}$ \\
+ PBO & 150 & $23(10-32)$ & $31(18-40)$ & $43(31-60)$ & $4.95 \pm 0.79$ & 2.46 & 0.90 \\
\hline
\end{tabular}

a. Propoxur and naled acute toxicity data, with and without synergists, presented as $\mathrm{LC}_{10}, \mathrm{LC}_{25}$, and $\mathrm{LC}_{50}$ with their $95 \%$ confidence intervals $(\mathrm{Cl})$ in micrograms per liter $(\mu \mathrm{g} / \mathrm{L})$, the concentrations at which 10,25 , and $50 \%$ of the tested larvae were dead, respectively, in a 24-h bioassay. Log-probit analysis was used to estimate the endpoint concentrations for each insecticide.

b. Pearson's chi-square $\left(\chi^{2}\right)$ values with a probability of $\chi^{2}>0.05$, which indicates that the observed regression model is not significantly different from the expected model (i.e., a significant fit between the observed and expected regression models).

c. Synergism ratio (SR) was calculated by $\mathrm{SR}=\mathrm{LC}_{50}$ insecticide only / $\mathrm{LC}_{50}$ insecticide-synergist mixture. The asterisk next to the ratio indicates a significant difference between the $L_{50}$ of the insecticide and the binary combination with a synergist based on the non-overlapping $95 \%$ confidence intervals of the $\mathrm{LC}_{50}$ values. 


\subsection{In vivo inhibition of enzyme activity}

\subsubsection{Inhibition of general esterase activity}

The in vivo inhibition of general esterase activity ( $\alpha$-naphthyl acetate hydrolysis) in third-instar Ae. aegypti larvae exposed to the $\mathrm{LC}_{25}$ of propoxur or naled alone and in combination with the synergists TPP and DEF at $2000 \mathrm{ppb}$ and $500 \mathrm{ppb}$ respectively, is shown in Fig. 1A. Significant differences due to insecticide treatment $(\mathrm{F}=38.48 ; \mathrm{df}=2$, $36 ; P<.0001)$ and synergist treatment $(\mathrm{F}=599.1 ; \mathrm{df}=2,36 ; P<.0001)$ were detected. The TPP and DEF treatments alone resulted in significant decreases of $89.6 \%(P<.0001)$ and $99.2 \%(P<.0001)$ in esterase specific activity, respectively, relative to the untreated control larvae. The propoxur treatment alone resulted in a significant decrease of $25.7 \%(P<.0001)$ in esterase specific activity relative to the untreated larvae. A significant reduction in esterase specific activity was observed in the larvae exposed to propoxur in combination with TPP or DEF. The TPP and DEF treatments resulted in decreases of $82.9 \%$ $(P<.0001)$ and $98.5 \%(P<.0001)$ in the esterase specific activity of propoxur, respectively, relative to the larvae treated with propoxur alone. The naled treatment alone resulted in a significant decrease of $55.3 \%(P<.0001)$ in esterase specific activity relative to the untreated larvae. A significant reduction in esterase specific activity was observed in the larvae exposed to naled in combination with TPP or DEF. The TPP and DEF treatments resulted in decreases of $98.6 \%(P<$ $.0001)$ and $98.6 \%(P<.0001)$ in the esterase specific activity of naled, respectively, relative to the larvae treated with naled alone.

\subsubsection{Inhibition of cytochrome P450 monooxygenase activity}

The in vivo inhibition of cytochrome P450 monooxygenase activity (O-deethylation) in third-instar Ae. aegypti larvae exposed to the $\mathrm{LC}_{25}$ of propoxur or naled alone and in combination with the synergist $\mathrm{PBO}$ at $2500 \mathrm{ppb}$ is shown in Fig. 1B. Significant differences due to insecticide treatment $(\mathrm{F}=3.531 ; \mathrm{df}=2,212 ; P=.0310)$ and synergist treatment $(\mathrm{F}=68.87 ; \mathrm{df}=1,212 ; P<.0001)$ were detected. The PBO treatment alone resulted in a significant decrease of 93.9\% $(P<.0001)$ in P450 activity, relative to the untreated control larvae. The propoxur treatment alone did not result in a significant change in P450 activity $(+6.8 \% ; P>.9999)$, relative to the untreated larvae. The PBO treatment in combination with propoxur resulted in a significant decrease 
A.

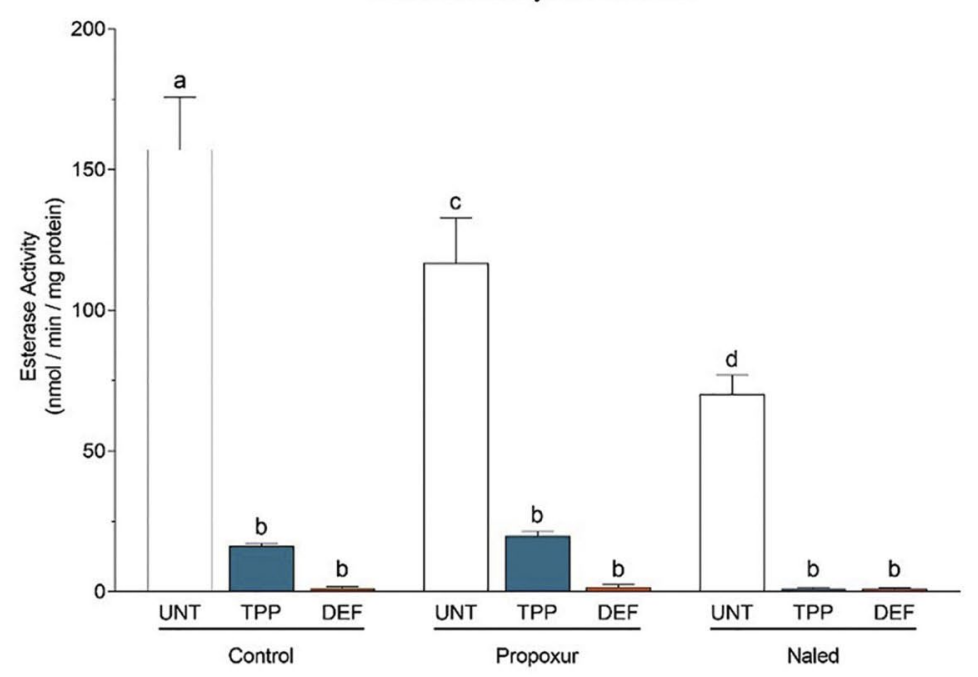

B.

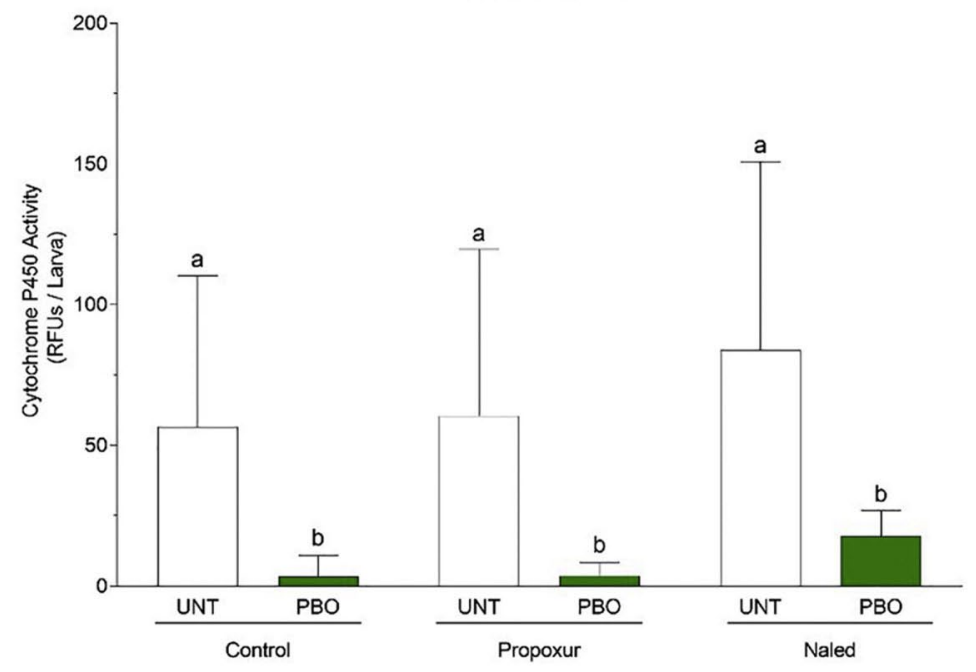

C.

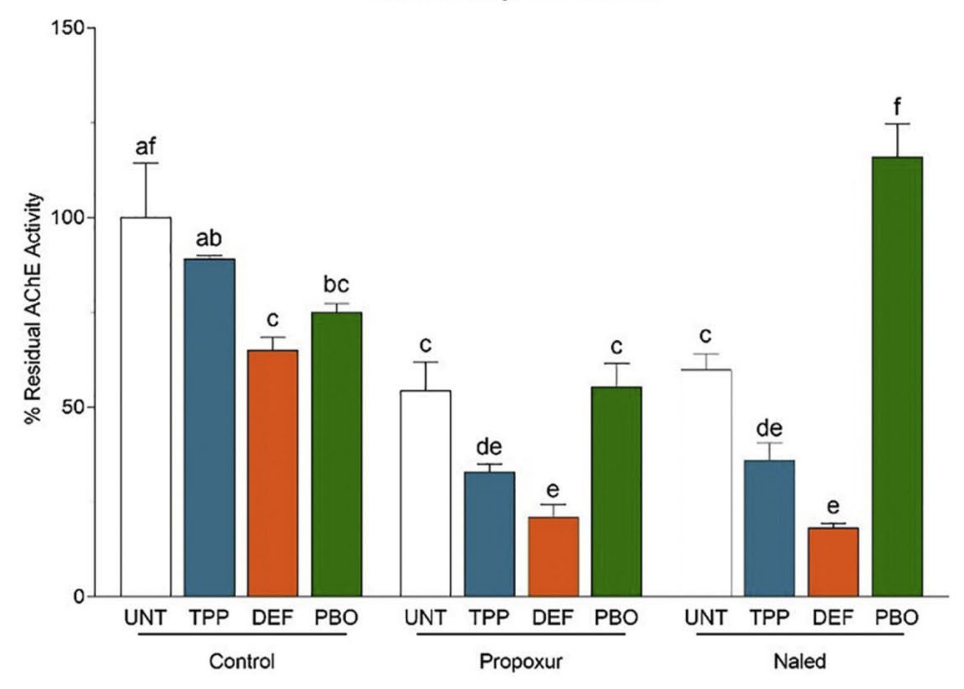

Fig. 1. Results of enzyme assays showing

A. in vivo inhibition of general esterase activity following treatment with the synergists triphenyl phosphate (TPP) and S,S,S-tributyl phosphorotrithioate (DEF),

B. in vivo inhibition of cytochrome P450 monooxygenase activity following treatment with the synergist piperonyl butoxide (PBO), and

C. residual acetylcholinesterase (AChE) activity following no treatment (UNT) or treatment with TPP, DEF, or $\mathrm{PBO}$ in third-instar Aedes aegypti larvae treated with propoxur or naled, relative to untreated controls. Enzyme activities are presented as the mean \pm standard deviation. Different letters above the bars indicate that the means are significantly different between the treatments using a twoway analysis of variance with a Sidak's multiple comparison test $(p<.05)$. 
of $94.0 \%(P=.0007)$ in $P 450$ activity, relative to treatment with propoxur alone. The larvae treated with naled alone did not display a significant change in $\mathrm{P} 450$ activity $(+47.9 \% ; P=.0827)$, relative to the untreated control larvae. The PBO treatment in combination with naled resulted in a significant decrease of $78.7 \%(P<.0001)$ in $\mathrm{P} 450$ activity, relative to the larvae treated with naled alone.

\subsubsection{Inhibition of acetylcholinesterase activity}

The residual acetylcholinesterase activity of third-instar Ae. aegypti larvae exposed to the $\mathrm{LC}_{10}$ of propoxur or naled alone and in combination with the synergists TPP, DEF, and PBO at 2000 ppb, 500 ppb, and 2500 ppb respectively, is shown in Fig. 1C. Significant differences due to insecticide treatment $(\mathrm{F}=94.73 ; \mathrm{df}=2,43 ; P<.0001)$ and synergist treatment $(\mathrm{F}=68.60 ; \mathrm{df}=3,43 ; P<.0001)$ were detected. The propoxur and naled treatments alone resulted in significant decreases of 48.7\% $(P<.0001)$ and $40.1 \%(P<.0001)$ in AChE activity, respectively, relative to the untreated control larvae. The DEF and PBO treatments alone resulted in significant decreases of 35.0\% $(P<.0001)$ and $25.1 \%$ $(P=.0083)$ in AChE activity, respectively, relative to the untreated larvae, however the $11.0 \%$ decrease observed in the larvae treated with TPP alone did not differ significantly $(P=.9631)$. Significant decreases in AChE activity were observed in the larvae exposed to propoxur or naled in combination with TPP. The TPP treatment in combination with propoxur or naled resulted in decreases of $39.4 \%(P=.0184)$ and $39.8 \%$ $(P=.0045)$ in AChE activity, respectively, relative to the larvae treated with propoxur or naled alone. Significant decreases in residual $A C h E$ activity were observed in the larvae exposed to propoxur or naled in combination with DEF. The DEF treatment in combination with propoxur or naled resulted in decreases of $61.3 \%(P<.0001)$ and $69.7 \%$ $(P<.0001)$ in AChE activity, respectively, relative to the larvae treated with propoxur or naled alone. A significant increase in AChE activity was observed in the larvae exposed to naled, but not propoxur, in combination with PBO. The PBO treatment in combination with propoxur did not produce a significant change in AChE activity (+1.9\%; $P>$.9999), whereas the PBO treatment in combination with naled resulted in an increase of $48.3 \%(P<.0001)$, relative to the larvae treated with propoxur or naled alone. 


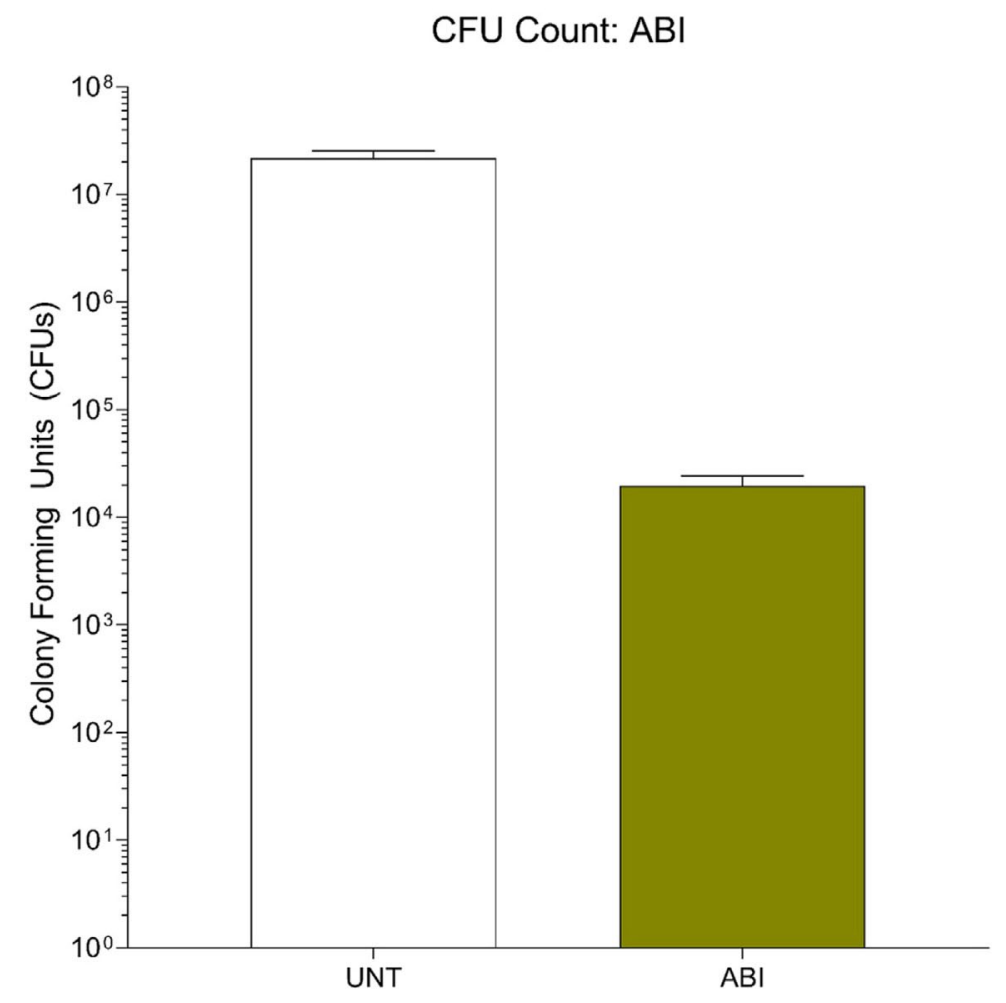

Fig. 2. Colony forming units of bacteria in untreated (UNT) and antibiotic (ABI)treated Aedes aegypti mosquito larvae, showing a 99.92\% reduction in the culturable bacteria. Bars represent the mean \pm standard deviation.

\subsection{Antibiotic optimization}

Treatment with a combination of the antibiotics gentamicin sulfate $(1500 \mu \mathrm{g} / \mathrm{mL})$, benzylpenicillin sodium (1000 units/mL), and streptomycin sulfate $(1 \mathrm{mg} / \mathrm{mL})$ resulted in a $99.92 \%$ reduction in the culturable bacteria isolated from Ae. aegypti mosquito larvae (Fig. 2).

\subsection{Acute toxicity of insecticides and antibiotics}

The results of the acute toxicity bioassays of insecticides alone and in combination with the antibiotic cocktail are summarized in Table 2. The combination of the antibiotics gentamicin sulfate $(1500 \mu \mathrm{g} / \mathrm{mL})$, benzylpenicillin sodium (1000 units $/ \mathrm{mL}$ ), and streptomycin sulfate $(1 \mathrm{mg} /$ $\mathrm{ml}$ ) was not acutely toxic to third-instar Ae. aegypti larvae under the bioassay conditions. The $\mathrm{LC}_{50}$ estimates for propoxur or naled alone or in combination with the antibiotics were used to calculate synergism 
Table 2. Effects of gentamycin $(1500 \mu \mathrm{g} / \mathrm{ml})$, penicillin $(1000 \mathrm{U} / \mathrm{ml})$, and streptomycin $(1000 \mu \mathrm{g} / \mathrm{ml})$ on the acute toxicity of propoxur and naled to third-instar Aedes aegypti larvae.

\begin{tabular}{llllllll} 
Insecticide & $N$ & $\mathrm{LC}_{10}(95 \% \mathrm{Cl})$ & $\mathrm{LC}_{25}(95 \% \mathrm{Cl})$ & $\mathrm{LC}_{50}(95 \% \mathrm{Cl})$ & Slope $\pm \mathrm{SE}$ & $\chi^{2 \mathrm{~b}}$ & $\mathrm{SRc}^{\mathrm{c}}$ \\
\hline Propoxur & 540 & $339(266-398)$ & $453(383-512)$ & $626(559-694)$ & $4.80 \pm 0.35$ & 2.43 & \\
+ Antibiotics & 150 & $134(54-189)$ & $173(146-195)$ & $239(213-265)$ & $4.99 \pm 0.69$ & 0.56 & $2.62^{*}$ \\
Naled & 900 & $17(15-20)$ & $25(22-28)$ & $38(35-43)$ & $3.69 \pm 0.21$ & 1.84 & \\
+ Antibiotics & 150 & $9(6-12)$ & $14(11-18)$ & $24(19-30)$ & $3.13 \pm 0.35$ & 1.36 & $1.58^{*}$ \\
\hline
\end{tabular}

a. Propoxur and naled acute toxicity data, with and without antibiotics, presented as $\mathrm{LC}_{10}, \mathrm{LC}_{25}$, and $\mathrm{LC}_{50}$ with their $95 \%$ confidence intervals $(\mathrm{Cl})$ in micrograms per liter $(\mu \mathrm{g} / \mathrm{L})$, the concentrations at which 10,25 , and $50 \%$ of the tested larvae were dead, respectively, in a 24-h bioassay. Log-probit analysis was used to estimate the endpoint concentrations for each insecticide.

b. Pearson's chi-square $\left(\chi^{2}\right)$ values with a probability of $\chi^{2}>0.05$, which indicates that the observed regression model is not significantly different from the expected model (i.e., a significant fit between the observed and expected regression models).

c. Synergism ratio (SR) was calculated by $\mathrm{SR}=\mathrm{LC}_{50}$ insecticide only $/ \mathrm{LC} \mathrm{C}_{50}$ insecticide-synergist mixture. The asterisk next to the ratio indicates a significant difference between the $\mathrm{LC}_{50}$ of the insecticide and the binary combination with a synergist based on the non-overlapping $95 \%$ confidence intervals of the $\mathrm{LC}_{50}$ values.

ratios. The toxicity of propoxur was significantly increased by 2.62 -fold and the toxicity of naled was significantly increased by 1.58 -fold when in combination with a fixed concentration of antibiotics.

\subsection{Effects of antibiotic treatments on enzyme activity}

\subsubsection{Inhibition of general esterase activity}

The in vivo inhibition of general esterase activity ( $\alpha$-naphthyl acetate hydrolysis) in third-instar Ae. aegypti larvae exposed to the $\mathrm{LC}_{25}$ of propoxur or naled alone and in combination with antibiotics, is shown in Fig. 3A. Significant differences due to insecticide treatment $(F=65.09$; $\mathrm{df}=2,24 ; P<.0001)$ and antibiotic treatment $(\mathrm{F}=38.84 ; \mathrm{df}=1,24$; $P<.0001)$ were detected. The propoxur and naled treatments alone resulted in significant decreases of $25.7 \%(P=.0002)$ and $55.3 \%$ $(P<.0001)$ in esterase specific activity, respectively, relative to the untreated control larvae. The antibiotic treatment alone resulted in a significant decrease of $21.9 \%(P=.0198)$ in esterase specific activity, relative to the untreated control larvae. A significant decrease in esterase specific activity of $50.6 \%(P<.0001)$ was observed in larvae that were exposed to propoxur in combination with antibiotics, relative to the larvae treated with propoxur alone. When mosquito larvae were exposed to naled in combination with antibiotics, however, there was 
A.

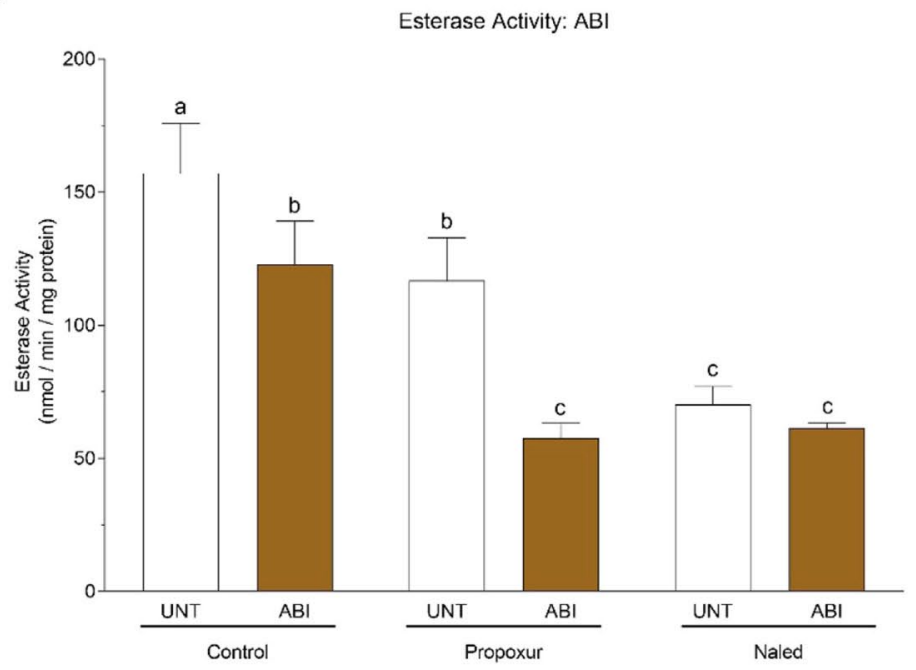

B.

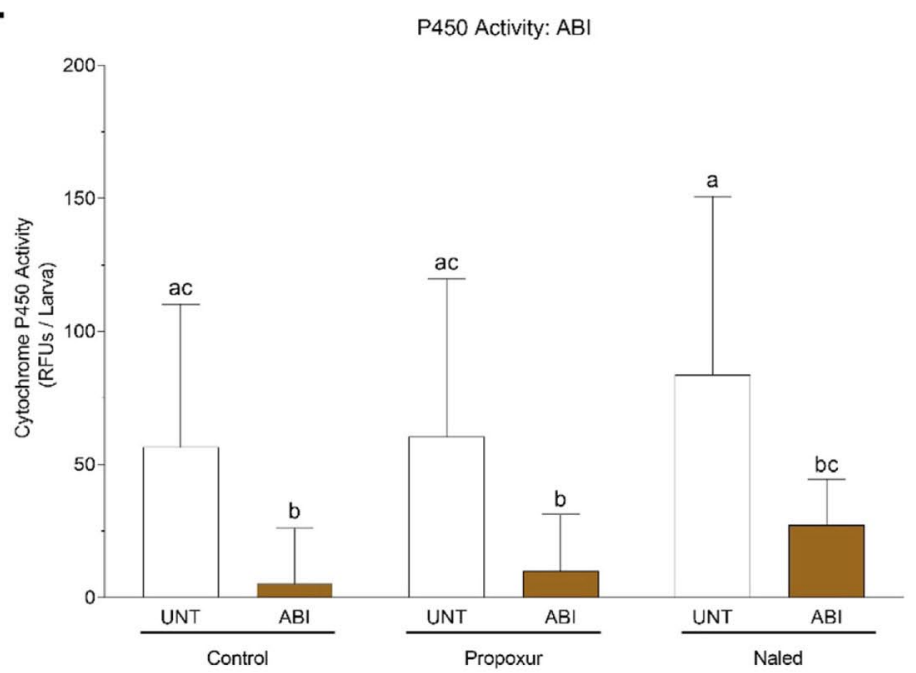

C.

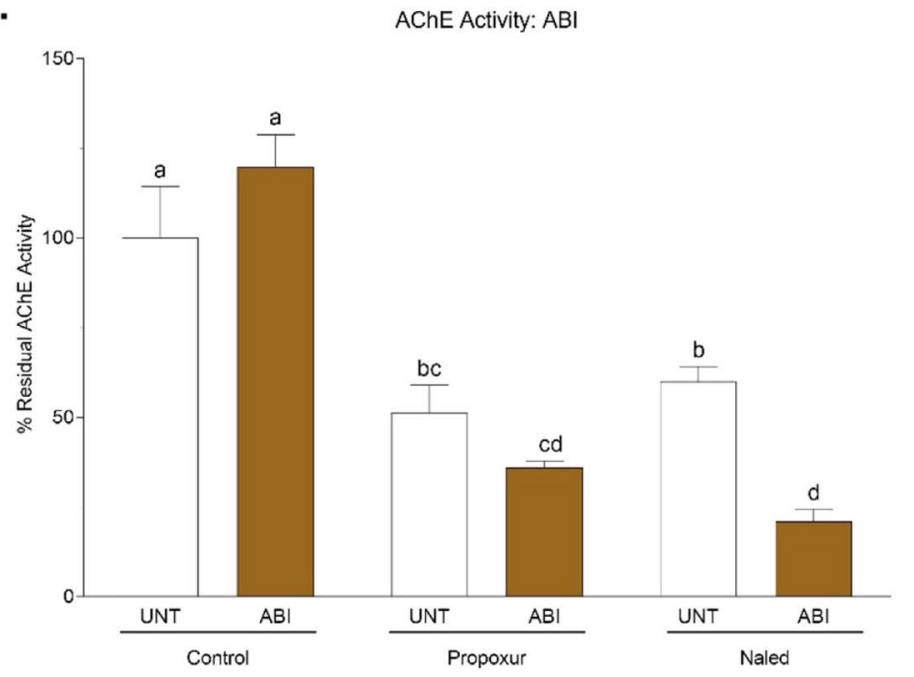

Fig. 3. Results of enzyme assays showing changes in

A. general esterase activity,

B. cytochrome P450 monooxygenase activity, and

C. residual acetylcholinesterase (AChE) activity in thirdinstar Aedes aegypti larvae left untreated (UNT) or treated with broadspectrum antibiotics (ABI), then exposed to propoxur or naled, relative to no mosquitocide treatment (Control). Enzyme activities are presented as the mean \pm standard deviation. Different letters above the bars indicate that the means are significantly different between the treatments using a twoway analysis of variance with a Sidak's multiple comparison test $(p<.05)$. 
only a slight and not significant decrease of $12.5 \%(P=.9988)$ in esterase specific activity, relative to the larvae treated with naled alone.

\subsubsection{Inhibition of cytochrome P450 monooxygenase activity}

The in vivo inhibition of cytochrome P450 monooxygenases (Odeethylation) in third-instar Ae. aegypti larvae exposed to the $\mathrm{LC}_{25}$ of propoxur or naled alone or in combination with antibiotics is shown in Fig. 3B. Significant differences due to insecticide treatment $(\mathrm{F}=3.686 ; \mathrm{df}=2,195 ; P=.0268)$ and antibiotic treatment $(\mathrm{F}=45.124$; $\mathrm{df}=1,195 ; P<.0001)$ were detected. The propoxur and naled treatments alone resulted in 6.3\% $(P>.9999)$ and $32.4 \%(P=.1311)$ increases in P450 activity, respectively, relative to the untreated larvae, however these increases were not significant. The antibiotic treatment alone resulted in a significant decrease of $90.7 \%(P=.0015)$ in P450 activity, relative to the untreated control larvae. The antibiotic treatment resulted in a significant decrease of $84.4 \%(P=.0060)$ in P450 activity when applied in combination with propoxur, relative to the larvae treated with propoxur alone. The antibiotic treatment also resulted in a significant decrease of $67.6 \%(P=.0010)$ in P450 activity when applied in combination with naled, relative to the larvae treated with naled alone.

\subsubsection{Inhibition of acetylcholinesterase activity}

The residual acetylcholinesterase activity of third-instar Ae. aegypti larvae exposed to the $\mathrm{LC}_{25}$ of propoxur or naled alone or in combination with antibiotics is shown in Fig. 3C. Significant differences due to insecticide treatment $(\mathrm{F}=165.6 ; \mathrm{df}=2,24 ; P<.0001)$ and antibiotic treatment $(\mathrm{F}=10.70 ; \mathrm{df}=1,24 ; P=.0032)$ were detected. The propoxur and naled treatments alone resulted in significant decreases of 48.7\% $(P<.0001)$ and $40.1 \%(P<.0001)$ in AChE activity, respectively, compared to the untreated larvae. The antibiotic treatment alone resulted in a $19.7 \%(P=.0517)$ increase in AChE activity that was not significant, relative to the untreated larvae. The antibiotic treatment in combination with propoxur resulted in a $29.7 \%(P=.2561)$ decrease in the AChE activity of treated larvae that was not significant, relative to the larvae treated with propoxur alone. The antibiotic treatment in combination with naled resulted in a significant decrease of $65.1 \%(P$ $<.0001)$ in the AChE activity of treated larvae, relative to the larvae treated with naled alone. 


\subsection{Insecticide degradation bioassays}

The results of the acute toxicity bioassays using insecticides that were subjected to potential bacterial metabolism are shown in Fig. 4. For the propoxur degradation experiment, significant differences due to

A.

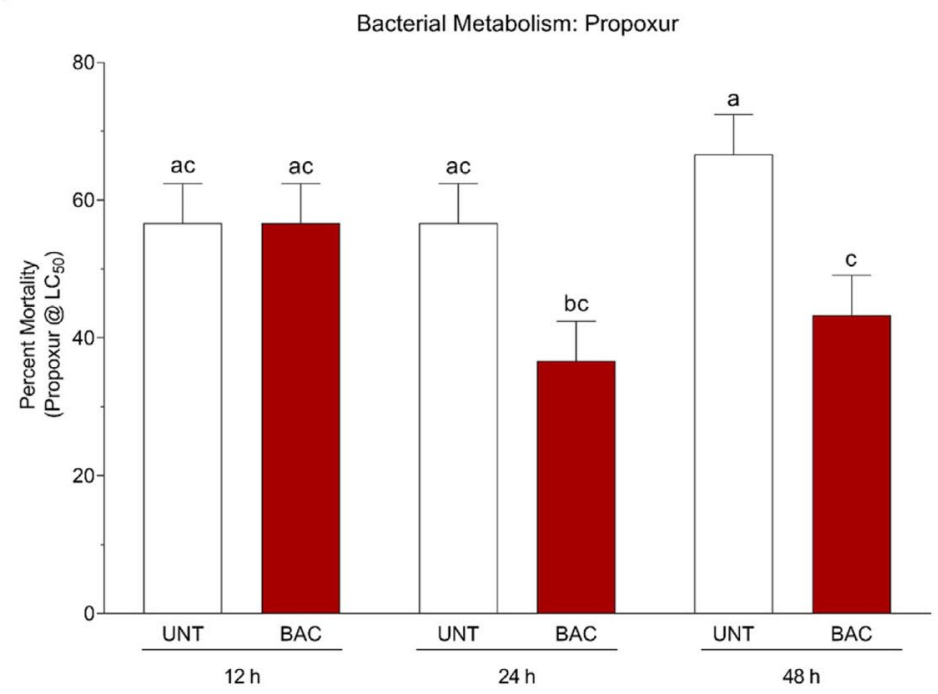

B.

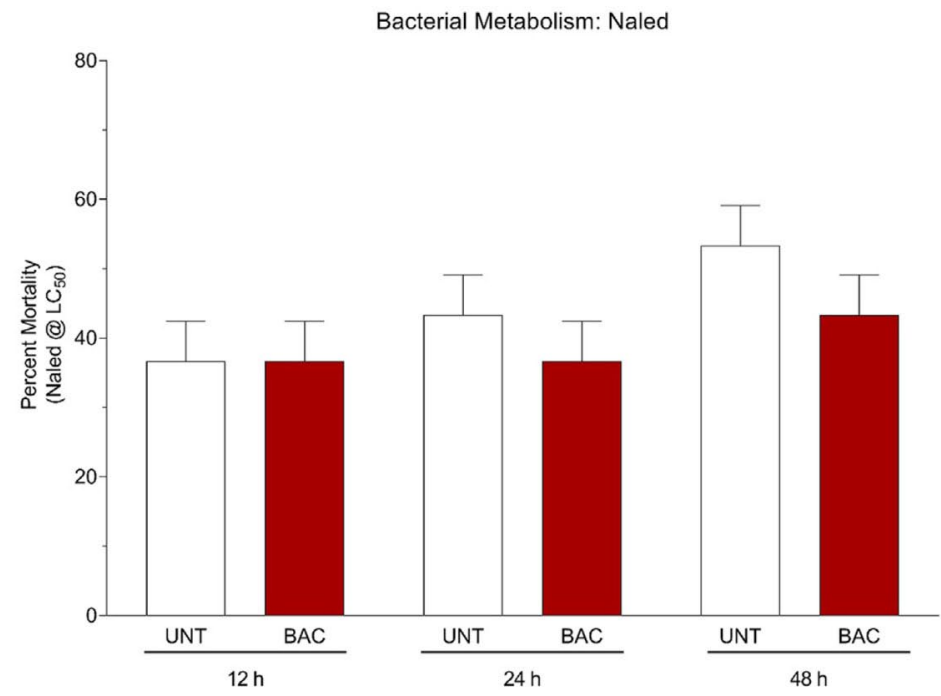

Fig. 4. Percent mortality of third-instar Aedes aegypti larvae treated with $\mathbf{A}$. bacteria-degraded (BAC) propoxur or B. bacteria-degraded naled. Bacteria cultures were treated with propoxur or naled and incubated for 12,24 , or $48 \mathrm{~h}$. Larvae were treated with a median lethal concentration (LC50) of each mosquitocide for $24 \mathrm{~h}$. Percent mortality is are presented as the mean \pm standard deviation. Different letters above the bars indicate that the means are significantly different between the treatments using a two-way analysis of variance with a Sidak's multiple comparison test $(p<.05)$. 
time $(\mathrm{F}=5.176 ; \mathrm{df}=2,12 ; P=.0239)$ and antibiotic treatment $(\mathrm{F}=28.23$; $\mathrm{df}=1,12 ; P=.0002)$ were detected. Mortality was significantly decreased by $35.3 \%(P=.0169)$ and $35.0 \%(P=.0050)$ in mosquito larvae treated with the $24 \mathrm{~h}$ and $48 \mathrm{~h}$ propoxur-bacteria inoculum, respectively, relative to the propoxur-only treatment. For the naled degradation experiment, significant differences due to time $(F=6.506 ; \mathrm{df}=2,12$; $P=.0122)$ and antibiotic treatment $(\mathrm{F}=4.172 ; \mathrm{df}=1,12 ; P=.0637)$ were detected. Mortality was decreased by $15.4 \%(P=.9515)$ and $18.8 \%$ $(P=.5733)$ in mosquito larvae treated with the $24 \mathrm{~h}$ and $48 \mathrm{~h}$ naledbacteria inoculum, respectively, compared to the naled-only treatment, but these changes were not significant.

\section{Discussion}

The goal of this study was to test the hypothesis that gut bacteria of Ae. aegypti larvae contribute to the metabolic detoxification and toxic action of the insecticides naled and propoxur. The acute toxicities of these insecticides to mosquito larvae, as well as the general esterase and P450 activities of the larvae, were assessed following treatment with insecticide synergists or broad-spectrum antibiotics. Additionally, the insecticides propoxur and naled were incubated with culturable bacteria isolated from Ae. aegypti larvae and then assessed for toxicity in order to demonstrate the bacterial capacity for metabolic detoxification of insecticides.

This study demonstrates that the acute toxicities of propoxur and naled were significantly increased for mosquito larvae that were exposed to the general esterase inhibitors TPP and DEF. In addition, the acute toxicity of propoxur was significantly increased for the mosquito larvae that were exposed to $\mathrm{PBO}$, whereas this synergist had no effect on the acute toxicity of naled to the mosquito larvae. This information expands our understanding of general esterase and P450-mediated metabolic detoxification and toxic action of standard-use insecticides such as naled and propoxur in mosquitoes, which appears to be influenced by the chemical structure of the insecticide. Hemingway et al. (Hemingway, 2000) report that general esterases are often associated with the reduced toxic action of carbamate and organophosphate insecticides, whereas P450s are more frequently associated with reduced toxic action of organophosphates than with carbamates. However, the 
findings of this study demonstrate that P450s are an important metabolic detoxification mechanism for mosquito larvae that were exposed to propoxur, but not for those larvae that were exposed to naled. Lykken and Casida (Lykken and Casida, 1969) report that P450s can facilitate the debromination of naled to the more toxic metabolite dichlorvos in insects. The acute toxicity of naled to mosquito larvae that were exposed to PBO suggests that the cytochrome P450 monooxygenase- mediated debromination of naled to dichlorvos may not be an important factor in the toxic action of the insecticide.

The anticholinesterase activities of propoxur and naled were significantly increased in mosquito larvae that were exposed to the mosquitocide synergists TPP and DEF. These data demonstrate that general esterases play an important role in the metabolic detoxification of propoxur and naled, consequently increasing the toxic action of these insecticides. Interestingly, the anticholinesterase activity of propoxur remained unchanged when exposed to the P450 inhibitor and insecticide synergist PBO, whereas the anticholinesterase activity of naled decreased. These findings support the idea that P450s do not play a major role in decreasing the toxic action of naled, but do not explain why inhibition of P450 activity would decrease the anticholinesterase activity of naled without altering the efficacy of the insecticide. Also puzzling is the observation that P450 inhibition due to PBO treatment significantly increased the efficacy of propoxur in the acute toxicity assays, but did not appear to alter the anticholinesterase activity of propoxur, which could suggest a different mechanism of toxicity. This is not the first time, however, that synergist bioassay data has conflicted with in vitro assays (Tsukamoto and Casida, 1967; Siegfried et al., 1990; Sanchez-Arroyo et al., 2001). Numerous studies have documented that co-application of synergists and insecticides can alter cuticular penetration rates, with examples of both decreased (Scott and Georghiou, 1986; Bull and Pryor, 1990; Sanchez-Arroyo et al., 2001) and increased (Sun and Johnson, 1972) rates of penetration. This suggests that one possible explanation for the discrepancy between the bioassay and in vitro data is that co-application of PBO is altering the pharmacokinetics of the insecticides. Another possible explanation is that these discrepancies are due to esterase inhibition by PBO. Khot et al. (Khot et al., 2008) revealed that PBO can create a blockade between insect anticholinesterases and other esterases to reduce the target-site activity of these compounds. 
This observation might explain the unaltered or reduced acetylcholinesterase inhibition of propoxur and naled in the PBO-treated $A e$. aegypti larvae, although a further examination of this mechanism is warranted for these mosquitoes.

This study also investigated the role of gut bacteria in the resistance of Ae. aegypti larvae to the insecticides propoxur and naled, based on the growing body of evidence that implicates the insect microbiome in metabolic detoxification of insecticides (Kikuchi et al., 2012; Gadad and Vastrad, 2016; Cheng et al., 2017; Soltani et al., 2017; Xia et al., 2018). The findings of this study demonstrate that reducing the number of bacterial colony-forming units in Ae. aegypti larvae with broad-spectrum antibiotics decreases the general esterase and P450 activities of the larvae, consequently decreasing the metabolic detoxification of propoxur and naled. Russell et al. (Russell et al., 2011) report that these metabolic detoxification enzymes are present in both carbamate- and organophosphate-degrading bacteria. These enzymes include the esterases MCD and CehA for the carbamate insecticides and phosphotriesterases, methyl parathion hydrolases, and organophosphorus acid anhydrolases for organophosphate insecticides (Russell et al., 2011). The esterases MCD, isolated from Achromobacter W111 (Derbyshire et al., 1987), and CehA, isolated from Rhizobium sp AC100 (Hashimoto et al., 2002), are reported to hydrolyze carboxylester bonds of 1 - naphthyl acetate. These enzymes are associated with organophosphate insecticide metabolism via hydrolysis of phosphoester bonds (Russell et al., 2011). It has also been suggested that there may exist an uncharacterized oxidative route for degradation of some organophosphate insecticides (Munnecke and Hsieh, 1976). In this study, an increase in acetylcholinesterase activity in Ae. aegypti larvae treated with the antibiotics, relative to the untreated mosquito larvae, was observed. However, the anticholinesterase activity of propoxur and naled was reduced in the antibiotic-treated Ae. aegypti larvae, relative to those mosquito larvae only treated with propoxur and naled. These results suggest that the bacteria in mosquito larvae may modify the toxic action of the insecticides.

Finally, this study examined the metabolic degradation of propoxur and naled using culturable bacteria isolated from Ae. aegypti larvae. Following the incubation of propoxur and naled with the culturable bacteria, the acute toxicity of propoxur to mosquito larvae was reduced, but no change was observed in the toxicity of naled. One 
possible explanation for this difference is that the bacteria responsible for assisting in the in vivo detoxification of naled in mosquito larvae were not able to be cultured with the protocol that was employed, and consequently were not present to degrade naled in vitro. Bacteria are reported to facilitate the metabolic detoxification of insecticides using enzyme systems that transform these compounds to carbon and energy sources for growth (Russell et al., 2011). Werren et al. (Werren, 2012) observed that bacteria are capable of metabolizing insecticides and utilizing the carbon, phosphorous, and nitrogen degradation products. Unfortunately, the bacteria cultures in this study were not analyzed for degradation products of propoxur and naled, therefore we are not able to definitively state that the culturable bacteria were responsible the metabolic detoxification of these insecticides in Ae. aegypti larvae, nor provide insight into the biochemical pathways that might have been utilized to modify the tested insecticides. While these findings do offer further support for the proposed hypothesis that bacterial endosymbionts may contribute to the metabolic detoxification of insecticides by mosquitoes, more work is required to fully elucidate the contribution of bacteria to the metabolic detoxification of insecticides in both Ae. aegypti larvae and adults.

In conclusion, the use of insecticides in agriculture and public health, as well as the presence of anthropogenic xenobiotics (e.g., antibiotics), may affect the microbial biodiversity of both the environment and the organisms that inhabit that environment. If antibiotic contamination is having an impact on the bacteria present in that environment, what effect does that contamination have on the bacterial community of the mosquito larvae in that environment? How does this affect the resistance of those mosquitoes to insecticides? The overall responses of mosquitoes to insecticides may be altered and the selection of insecticide resistance mechanisms may occur as a consequence. In this context, future studies should be performed that focus on better understanding insecticide resistance mechanisms in mosquito larvae, with regard to the mosquito microbiome, and compiling data on the impact of environmental factors on the biodiversity of mosquito gut bacteria in an effort to explain how these factors might influence insecticide resistance. Because these studies were conducted using laboratoryreared Ae. aegypti larvae, it is possible that the results observed in this study could be more or less pronounced in natural mosquito populations as a result of the different exposure that the natural populations 
would have to microbe-rich habitats. A valuable future direction of this work would be to examine the evolution of resistance in mosquito populations in the context of both larval habitat and the diversity of the mosquito microbiome. Furthermore, it would be pertinent to identify various environmental factors (i.e. insecticide application, chemical leaching, etc.) that may contribute to these differences and establish relevant trends. The information gained from this work could be used to 1) improve current toxicodynamic and toxicokinetic models for established and experimental insecticidal chemistries, 2) develop more effective, sustainable, and targeted vector control interventions, and 3) highlight the potential environmental impacts of mosquito usage in public health and agriculture.

Author contributions - Conceptualization: SSS, TDA. Investigation: SSS, TDA. Formal Analysis: SSS, STO, TDA. Original Draft Preparation: SSS, STO, TDA. Review and Editing: SSS, STO, TDA.

Declaration of Competing Interest - The authors declared no competing financial interests.

Acknowledgments - This research did not receive any specific grant from funding agencies in the public, commercial, or not-for-profit sectors.

\section{References}

Abbott, W.S., 1925. A method of computing the effectiveness of an insecticide. J. Econ. Entomol. 18, 265-267.

Anderson, T.D., Zhu, K.Y., 2004. Synergistic and antagonistic effects of atrazine on the toxicity of organophosphorodithioate and organophosphorothioate insecticides to Chironomus tentans (Diptera: Chironomidae). Pestic. Biochem. Physiol. 80, 54-64.

Anderson, T.D., Paulson, S.L., Wong, D.M., Carlier, P.R., Bloomquist, J.R., 2009. Pharmacological Mapping of the Acetylcholinesterase Catalytic Gorge in Mosquitoes with bis(N)-Tacrines, Pp. 143-151, Advances in Human Vector Control, Vol. 1014. American Chemical Society.

Bernard, C.B., Philogène, B.J.R., 1993. Insecticide synergists: role, importance, and perspectives. J. Toxicol. Environ. Health 38, 199-223.

Bull, D.L., Pryor, N.W., 1990. In vivo and in vitro fate of fenvalerate in house flies. Pestic. Biochem. Physiol. 38, 140-152.

Casida, J.E., Quistad, G.B., 2004. Why insecticides are more toxic to insects than people: the unique toxicology of insects. J. Pestic. Sci. 29, 81-86.

Cheng, D., Guo, Z., Riegler, M., Xi, Z., Liang, G., Xu, Y., 2017. Gut symbiont enhances insecticide resistance in a significant pest, the oriental fruit fly Bactrocera dorsalis (Hendel). Microbiome 5, 13. 
Derbyshire, M.K., Karns, J.S., Kearney, P.C., Nelson, J.O., 1987. Purification and characterization of an $\mathrm{N}$-methylcarbamate pesticide hydrolyzing enzyme. J. Agric. Food Chem. 35, 871-877.

Dillon, R.J., Dillon, V.M., 2004. The gut bacteria of insects: nonpathogenic interactions. Annu. Rev. Entomol. 49, 71-92.

Dong, Y., Manfredini, F., Dimopoulos, G., 2009. Implication of the mosquito midgut microbiota in the defense against malaria parasites. PLoS Pathog. 5, e1000423.

Eleftherianos, I., Atri, J., Accetta, J., Castillo, J.C., 2013. Endosymbiotic bacteria in insects: guardians of the immune system? Front. Physiol. 4, 46.

Ellman, G.L., Courtney, K.D., Andres, V., Featherstone, R.M., 1961. A new and rapid colorimetric determination of acetylcholinesterase activity. Biochem. Pharmacol. 7, 88-95.

Gadad, H., Vastrad, A.S., 2016. Gut bacteria mediated insecticide resistance in Spodoptera litura (fab.). J. Exper. Zoology, India 19, 1099-1102.

Haine, E.R., 2008. Symbiont-mediated protection. Proc. Biol. Sci. 275, 353-361.

Hashimoto, M., Fukui, M., Hayano, K., Hayatsu, M., 2002. Nucleotide sequence and genetic structure of a novel carbaryl hydrolase gene (cehA) from Rhizobium sp. strain AC100. Appl. Environ. Microbiol. 68, 1220-1227.

Hedges, L.M., Brownlie, J.C., O'Neill, S.L., Johnson, K.N., 2008. Wolbachia and virus protection in insects. Science 322, 702.

Hemingway, J., 2000. The molecular basis of two contrasting metabolic mechanisms of insecticide resistance. Insect Biochem Molec 30, 1009-1015.

Hemingway, J., Beaty, B.J., Rowland, M., Scott, T.W., Sharp, B.L., 2006. The innovative vector control consortium: improved control of mosquito-borne diseases. Trends Parasitol. 22, 308-312.

Hoffmann, A.A., Montgomery, B.L., Popovici, J., Iturbe-Ormaetxe, I., Johnson, P.H., Muzzi, F., Greenfield, M., Durkan, M., Leong, Y.S., Dong, Y., Cook, H., Axford, J., Callahan, A.G., Kenny, N., Omodei, C., McGraw, E.A., Ryan, P.A., Ritchie, S.A., Turelli, M., O'Neill, S.L., 2011. Successful establishment of Wolbachia in Aedes populations to suppress dengue transmission. Nature 476, 454.

Khot, A.C., Bingham, G., Field, L.M., Moores, G.D., 2008. A novel assay reveals the blockade of esterases by piperonyl butoxide. Pest Manag. Sci. 64, 1139-1142.

Kikuchi, Y., Hayatsu, M., Hosokawa, T., Nagayama, A., Tago, K., Fukatsu, T., 2012. Symbiont-mediated insecticide resistance. Proc. Natl. Acad. Sci. 109, 8618-8622.

Lederberg, J., 1950. Isolation and characterization of biochemical mutants of Bacteria. Meth Med Res 3, 5-22.

Lykken, L., Casida, J.E., 1969. Metabolism of organic insecticide chemicals. Can. Med. Assoc. J. 100, 145-154.

Matthews, H.B., Casida, J.E., 1970. Properties of housefly microsomal cytochromes in relation to sex, strain, substrate specificity, and apparent inhibition and induction by synergist and insecticide chemicals. Life Sci. 9, 989-1001.

Moran, N.A., 2007. Symbiosis as an adaptive process and source of phenotypic complexity. Proc. Natl. Acad. Sci. 104, 8627-8633.

Morrison, A.C., Zielinski-Gutierrez, E., Scott, T.W., Rosenberg, R., 2008. Defining challenges and proposing solutions for control of the virus vector Aedes aegypti. PLoS Med. 5, e68. 
Munnecke, D.M., Hsieh, D.P., 1976. Pathways of microbial metabolism of parathion. Appl. Environ. Microbiol. 31, 63-69.

Pridgeon, J.W., Bernier, U.R., Becnel, J.J., 2009. Toxicity Comparison of Eight Repellents against Four Species of Female Mosquitoes. vol. 25 BIOONE.

Rakotondravelo, M.L., Anderson, T.D., Charlton, R.E., Zhu, K.Y., 2006. Sublethal effects of three pesticides on activities of selected target and detoxification enzymes in the aquatic midge, Chironomus tentans (Diptera: Chironomidae). Arch. Environ. Contam. Toxicol. 51, 360.

Russell, R.J., Scott, C., Jackson, C.J., Pandey, R., Pandey, G., Taylor, M.C., Coppin, C.W., Liu, J.-W., Oakeshott, J.G., 2011. The evolution of new enzyme function: lessons from xenobiotic metabolizing bacteria versus insecticide-resistant insects. Evol. Appl. 4, 225-248.

Sanchez-Arroyo, H., Koehler, P.G., Valles, S.M., 2001. Effects of the synergists piperonyl butoxide and S,S,S-tributyl phosphorotrithioate on propoxur pharmacokinetics in Blattella germanica (Blattodea: Blattellidae). J. Econ. Entomol. 94, 1209-1216.

Scott, J.G., Georghiou, G.P., 1986. Mechanisms responsible for high levels of permethrin resistance in the house fly. Pestic. Sci. 17, 195-206.

Siegfried, B.D., Scott, J.G., Roush, R.T., Zeichner, B.C., 1990. Biochemistry and genetics of chlorpyrifos resistance in the German cockroach, Blattella germanica (L). Pestic. Biochem. Physiol. 38, 110-121.

Smith, P.K., Krohn, R.I., Hermanson, G.T., Mallia, A.K., Gartner, F.H., Provenzano, M.D., Fujimoto, E.K., Goeke, N.M., Olson, B.J., Klenk, D.C., 1985. Measurement of protein using bicinchoninic acid. Anal. Biochem. 150, 76-85.

Soltani, A., Vatandoost, H., Oshaghi, M.A., Enayati, A.A., Chavshin, A.R., 2017. The role of midgut symbiotic bacteria in resistance of Anopheles stephensi (Diptera: Culicidae) to organophosphate insecticides. Pathog. Global Health 111, 289-296.

Sun, Y.-P., Johnson, E.R., 1972. Quasi-synergism and penetration of insecticides. J. Econ. Entomol. 65, 349-353.

Tsukamoto, M., Casida, J.E., 1967. Albumin enhancement of oxidative metabolism of methylcarbamate insecticide chemicals by the house fly microsome$\mathrm{NADPH}_{2}$ system. J. Econ. Entomol. 60, 617-619.

Weill, M., Fort, P., Berthomieu, A., Dubois, M.P., Pasteur, N., Raymond, M., 2002. A novel acetylcholinesterase gene in mosquitoes codes for the insecticide target and is nonhomologous to the ace gene in Drosophila. Proc. Biol. Sci. 269, 2007-2016.

Werren, J.H., 2012. Symbionts provide pesticide detoxification. Proc. Natl. Acad. Sci. 109, 8364-8365.

Werren, J.H., Baldo, L., Clark, M.E., 2008. Wolbachia: master manipulators of invertebrate biology. Nat. Rev. Microbiol. 6, 741.

Xia, X., Sun, B., Gurr, G.M., Vasseur, L., Xue, M., You, M., 2018. Gut microbiota mediate insecticide resistance in the diamondback moth, Plutella xylostella (L.). Front. Microbiol. 9. 